\title{
Sitosterolemia Presenting as Pseudohomozygous Familial Hypercholesterolemia
}

\author{
Christian Renner, MD; William E. Connor, MD; and Robert D. Steiner, MD
}

\begin{abstract}
A young girl, age 8.5 years, presented with profound hypercholesterolemia and early xanthomatosis, suggesting homozygous familial (or type II) hypercholesterolemia. The patient's low density lipoprotein $(\mathrm{LDL})$ receptor function and parental lipoprotein profiles were determined to be normal, prompting revision of the initial diagnosis to pseudohomozygous familial hypercholesterolemia. When she subsequently presented with giant platelets, the case was presented to colleagues on an electronic mailing list. It was recommended that plasma and sterol analysis be performed, which led to a diagnosis of sitosterolemia. The presentation of profound hypercholesterolomia in childhood that ultimately is not attributed as due to homozygous or compound heterozygous defects in the LDL receptor gene has been termed pseudohomozygous familial (or type II) hypercholesterolemia (PHT2HC). Patients diagnosed with $\mathrm{PHT} 2 \mathrm{HC}$ subsequently confirmed to have sitosterolemia have been previously reported only rarely. The challenge of achieving accurate specific diagnosis and appropriate workup for these conditions in children is discussed in the context of this rare case and review of the historical literature concerning these conditions.
\end{abstract}

Keywords: Sitosterolemia; Pseudohomozygous type II hypercholesterolemia; Familial hypercholesterolemia

$\mathrm{T}$ The rare autosomal recessive disease sitosterolemia was first described by one of the authors (WEC) and his colleague in a 1974 report of two sisters presenting with xanthomas and abnormally high plasma and tissue levels of plant sterols, particularly sitosterol. ${ }^{1}$ Normally present in only trace amounts in plasma, dietary plant sterols (phytosterols) are largely excreted from the body and very poorly reabsorbed. In patients diagnosed with sitosterolemia, plant dietetic sterols are not optimally excreted, resulting in a 30-100 fold increase in plasma sterol levels. Inability to process sterols ultimately results in tissue deposition and potential xanthoma formation. ${ }^{2-4}$

Because of shared clinical features, when hypercholesterolemia is profound, sitosterolemia may be erroneously diagnosed as homozygous familial hypercholesterolemia - also referred to as pseudohomozygous type II hypercholesterolemia (PHT2HC) - based on cholesterol levels and xanthomas. However, these conditions have very distinct etiologies, are associated with variable atherogenic risk, and require divergent clinical management, emphasizing the need for accurate diagnosis. Diagnosis of sitosterolemia in children presenting with elevated cholesterol and early xanthomatosis is critical, since the low fat/low cholesterol diet likely to be prescribed in the context of a hypercholesterolemia diagnosis is high in vegetable oil content, which could exacerbate the metabolic derangements associated with sitosterolemia. We report a pediatric patient with suspected (PHT2HC) who was eventually correctly diagnosed with sitosterolemia that was confirmed by biochemical analysis demonstrating elevated plasma levels of phytosterols. ${ }^{1}$

\section{Case Report}

A young girl, age 8.5 years, the only child of healthy, nonconsanguineous, caucasian parents, was referred to the Universitätsklinik für Kinder und Jugendliche, Erlangen, Germany, Metabolic Division, with findings of profound hypercholesterolemia. At approximately age 12 months, a tuberous xanthoma over the left knee had been observed and excised. Subsequently, xanthomas had redeveloped over the knees (about $0.5 \mathrm{~cm}$ in diameter) and buttocks. The xanthomas, which were firm with a smooth surface and without an
Corresponding Author: Dr. med Christian Renner, Kinder- und Jugenarztpraxis, Pfleggasse 3I, D-94469 Deggendorf, Germany, Tel: +991 - 31450,

Email: cjrenner@well.com
Received: June 16,2015

Revised: January 26, 2016

Accepted: February 5, 2016 


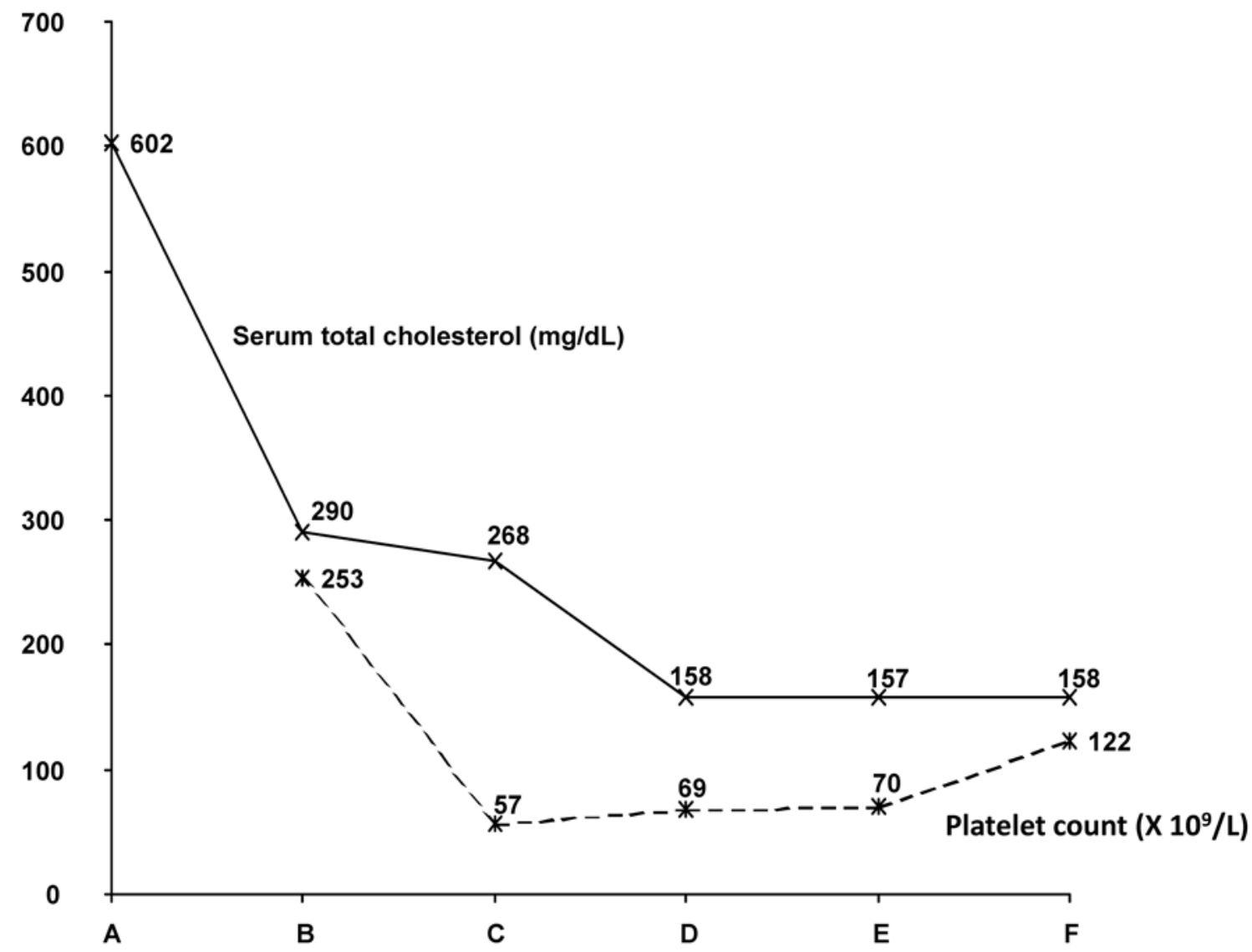

Figure 1. Plasma cholesterol and blood platelet count (for plant sterols see Table 1). A: initial presentation; B: 6-month control on low-fat, high-vegetable-oil diet; C: 12-month control on high-vegetable-oil diet: diagnosis; D: 8 weeks on low-fat/sterol diet; E: 8 weeks on diet plus oral cholestyramine; F: 1 year on diet plus oral cholestyramine.

erythematous base, developed within weeks and were classifiable as tubero-eruptive. Initial plasma lipoprotein analysis (figure 1A) measured total plasma cholesterol at $602 \mathrm{mg} / \mathrm{dL}(15.6 \mathrm{mmol} / \mathrm{L})$ with normal triglycerides at $85 \mathrm{mg} /$ $\mathrm{dL}(0.96 \mathrm{mmol} / \mathrm{L})$. A low-fat diet (approximately $30-35 \%$ of total daily caloric intake) had already been started by the patient's pediatrician.

Apart from the xanthomas, the physical examination was unremarkable. No corneal arcus was present. ${ }^{5}$ The patient was generally in good health having developed normally, with height and weight at the $50^{\text {th }}$ and $25^{\text {th }}$ percentile, respectively, for European girls. Outside of a maternal grandfather who had undergone coronary bypass surgery at age 55, no familial history of atherosclerotic disease or premature death was noted.

The child showed mild microcytic anemia (blood hemoglobin $1.6 \mathrm{mmol} / \mathrm{L}$, hematocrit 34\%) with signs of latent iron deficiency (plasma iron $40 \mu \mathrm{mol} / \mathrm{L}$, transferrin $2.6 \mathrm{~g} / \mathrm{L}$, ferritin $17 \mu \mathrm{g} / \mathrm{L}$ ), with otherwise unremarkable laboratory evaluations at her initial evaluation (figure 1B) including platelet count $\left(253 \times 10^{9} / \mathrm{L}\right)$, blood leucocytes, renal, liver, and thyroid function parameters, blood glucose, hemoglobin A1c, coagulation parameters, plasma triglycerides, plasma homocystine, and urinalysis. Electrocardiogram and echocardiography were normal.

Lipoprotein electrophoresis showed total plasma cholesterol levels of $290 \mathrm{mg} / \mathrm{dL}(7.5 \mathrm{mmol} / \mathrm{L})$, low density lipoprotein (LDL)-cholesterol at $262 \mathrm{mg} / \mathrm{dL}(6.8 \mathrm{mmol} / \mathrm{L})$, high density lipoprotein (HDL)-cholesterol $23 \mathrm{mg} / \mathrm{dL}(0.61 \mathrm{mmol} / \mathrm{L})$, and very low density lipoprotein (VLDL)-cholesterol $6 \mathrm{mg} / \mathrm{dL}$ $(0.2 \mathrm{mmol} / \mathrm{L})$. However, plasma apolipoprotein B levels were elevated at $226 \mathrm{mg} / \mathrm{dL}$, (normal value $<155 \mathrm{mg} / \mathrm{dl}$ ). Lipoprotein Lp(a)-RIA was normal $(20 \mathrm{mg} / \mathrm{dL})$ and plasma apolipoprotein E phenotype was classified as E3/E3. Familial defective Apo B-100 was excluded by mutational screening.

Unexpectedly, both parents had completely normal lipoprotein status (total cholesterol level of the father was measured at $189 \mathrm{mg} / \mathrm{dL}$ [4.9 mmol/L], and the mother's was measured at $182 \mathrm{mg} / \mathrm{dL}$ [4.9 mmol/L]). LDL-receptor investigation using a previously published cultured fibroblast approach ${ }^{6}$ exhibited full functionality, thereby ruling out diagnosis of familial hypercholesterolemia.

Dietary low-fat therapy led to a remarkable and surprising improvement in lipoprotein status. That diet was continued, somewhat modified to include a higher proportion of vegetable 
oils, especially mono-unsaturated fatty acids (olive oil). For anti-oxidative protection, alpha-tocopherol capsules, $400 \mathrm{IE}$ per day in a plant oil preparation, were prescribed.

The patient was provisionally diagnosed as PHT2HC based on the following criteria: (1) severe hypercholesterolemia as seen in homozygous familial hypercholesterolemia with early xanthoma development; (2) exclusion of potential secondary causes of hypercholesterolemia; (3) no lipid abnormalities in first-degree relatives; (4) normal fibroblast LDL receptor activity; and (5) good response to dietary therapy. ${ }^{7-9}$ Cerebrotendinous xanthomatosis, which can also present with xanthomas early in life, was ruled out by the profound hypercholesterolemia and the sterol analysis showing diagnostic elevation of plant sterol levels.

Six months later (figure 1C), plasma lipoprotein status showed further improvement (total cholesterol $268 \mathrm{mg} / \mathrm{dL}$ [6.91 mmol/L]; LDL-cholesterol $212 \mathrm{mg} / \mathrm{dl}$ [5.5 mmol/L]; HDL-cholesterol $69 \mathrm{mg} / \mathrm{dL}[1.8 \mathrm{mmol} / \mathrm{L}])$. No new xanthomas had developed, and the existing ones had slightly decreased in size and become paler. Liver function, renal function, and coagulation parameters were still normal. Total blood cell count, though, showed thrombocytopenia with $96 \times 10^{9} / \mathrm{L}$ platelets $/ \mathrm{cm}^{3}$ that subsequently decreased to $50 \times 10^{9} / \mathrm{L}$ platelets $/ \mathrm{cm}^{3}$ during the following 2 months. Bone marrow examination showed no signs of malignany or insuffiency, and bone marrow megakaryocytes were normal in number and appearance. Peripheral platelet size distribution as described by the automatic Coulter blood cell counter indicated platelets were increased in size while platelet in vitro aggregation was normal.

Prompted by discussion of the case on the "Metab-L" electronic mailing list for inborn errors of metabolism, ${ }^{10}$ plasma plant sterols were measured by gas chromatography ${ }^{1,4}$ and found to be markedly elevated: sitosterol $20.7 \mathrm{mg} / \mathrm{dL}$ (normal values $0.33 \pm 0.03 \mathrm{mg} / \mathrm{dL}$ ), campesterol $9.1 \mathrm{mg} / \mathrm{dL}$ (normal $0.55 \pm 0.04 \mathrm{mg} / \mathrm{dL}$ ), stigmasterol $1.1 \mathrm{mg} / \mathrm{dL}$ (normally undetectable or trace), total plasma plant sterols $37.9 \mathrm{mg} / \mathrm{dL}$ (normal $0.67 \pm 0.09 \mathrm{mg} / \mathrm{dL}$ ), $19 \%$ of total plasma sterols. Plasma cholestanol $(3.0 \mathrm{mg} / \mathrm{dL}$, normal $0.41 \pm 0.17 \mathrm{mg} / \mathrm{dL})$, sitostanol $(5.5 \mathrm{mg} / \mathrm{dL})$, and campestanol $(1.5 \mathrm{mg} / \mathrm{dL})$ were also markedly elevated (Table 1). Plasma sterol composition of both the mother (sitosterol $0.2 \mathrm{mg} / \mathrm{dL}$, campesterol $0.6 \mathrm{mg}$ / $\mathrm{dL}$; stigmasterol, cholestanol, sitostanol and campestanol not detectable) and father (sitosterol $0.1 \mathrm{mg} / \mathrm{dL}$, campesterol $0.1 \mathrm{mg} / \mathrm{dL}$; stigmasterol, cholestanol, sitostanol and campestanol not detectable) were normal.

With a diagnosis of sitosterolemia established, dietary therapy was completely changed to a low total fat $(30 \%$ of total daily caloric intake) and low vegetable oil scheme ${ }^{2}$ that proved challenging for daily compliance. Further improvements were noted in plasma total cholesterol $(155 \mathrm{mg} / \mathrm{dL}[4.0$ $\mathrm{mmol} / \mathrm{L}]$, LDL-cholesterol $109 \mathrm{mg} / \mathrm{dL}$ [2.8 mmol/L], HDLcholesterol $44.1 \mathrm{mg} / \mathrm{dL}$ [1.14 mmol/L] 8 weeks after low plant sterol diet was prescribed, but platelet counts remained low, and no reduction in plasma plant sterols was noted. Cholestyramine ( $16 \mathrm{~g} /$ day, $0.5 \mathrm{~g} / \mathrm{kg}$ ) was added as a therapeutic intervention based on previous demonstration of responsiveness to this adjunctive therapy in a case presenting with a similar clinical profile. ${ }^{11}$ Total cholesterol remained at $157 \mathrm{mg} / \mathrm{dL}(4.0 \mathrm{mmol} / \mathrm{L}) 8$ weeks following initiation of cholestyramine therapy, while platelet counts remained unchanged; however, plasma plant sterols were decreased $>50 \%$ (sitosterol $14.6 \mathrm{mg} / \mathrm{dL}$, campesterol $5.0 \mathrm{mg} / \mathrm{dL}$, stigmasterol $0.5 \mathrm{mg} / \mathrm{dL}$, total plasma plant sterols $24.4 \mathrm{mg} /$ dL) with plasma cholestanol non-detectable, sitostanol at $3.8 \mathrm{mg} / \mathrm{dL}$, and campestanol at $0.5 \mathrm{mg} / \mathrm{dL}$ (figure $1 \mathrm{E}$ ). Buttock and knee xanthomas vanished within 6 months postcholestyramine therapy initiation, leaving only reddish scarlike marks. One year post-cholestyramine initiation, platelet counts measured $122 \times 10^{9} / \mathrm{L}$ (figure $1 \mathrm{~F}$ ).

\section{Discussion}

Over the past 50 years, research has more clearly elucidated the underlying causes of several conditions impacting on lipid

Table 1: Course of plasma sterol elevation

\begin{tabular}{|c|c|c|c|c|c|}
\hline \multirow[b]{3}{*}{ Sterol } & \multirow[b]{2}{*}{ Normal Values } & \multicolumn{4}{|c|}{ Treatment (see figure 1) } \\
\hline & & $\begin{array}{c}\text { High vegetable } \\
\text { oil diet } \\
\text { (C=12 months) }\end{array}$ & $\begin{array}{c}\text { Low fat / sterol } \\
\text { diet } \\
\text { (D=8 weeks ) }\end{array}$ & $\begin{array}{c}\text { Diet + } \\
\text { cholestyramine } \\
\text { (E=8 weeks) }\end{array}$ & $\begin{array}{c}\text { Diet }+ \\
\text { cholestyramine } \\
\text { (F=12 months) }\end{array}$ \\
\hline & $\mathrm{mg} / \mathrm{dL}$ & $\mathrm{mg} / \mathrm{dL}$ & $\mathrm{mg} / \mathrm{dL}$ & $\mathrm{mg} / \mathrm{dL}$ & $\mathrm{mg} / \mathrm{dL}$ \\
\hline Sitosterol & $0.33 \pm 0.03$ & 20.7 & 26.2 & 16.9 & 15.3 \\
\hline Campesterol & $0.55 \pm 0.04$ & 9.1 & 12.8 & 5.0 & 5.6 \\
\hline Stigmasterol & undetectable or trace & 1.1 & 1.1 & 0.5 & 0.5 \\
\hline Cholesterol & $100-170$ & 268.0 & 158.0 & 157.0 & 157.0 \\
\hline Cholestanol & $0.41 \pm 0.17$ & 3.0 & 2.7 & trace & trace \\
\hline 5-a Sitostanol & & 5.5 & 7.5 & 3.8 & 3.9 \\
\hline 5-a Campestanol & & 9.1 & 12.8 & 5.0 & 0.7 \\
\hline
\end{tabular}


metabolism that may present with similar clinical features, but that require divergent clinical management based on the etiology of the conditions. The most common of these conditions, familial hypercholesterolemia, is a heritable condition arising from functional mutations of genes whose products are associated with lipid processing. ${ }^{12,13}$ The most commonly reported mutations impact the LDL receptor gene $(L D L R)$, resulting in receptors with reduced capacity to process LDL. ${ }^{12,13}$ Less frequently observed mutations associated with familial hypercholesterolemia have also been defined and occur at the level of $A P O B$, and gain-of-function mutations in PCSK9, whose gene products support normal functioning of the LDL receptor. Autosomal recessive LDL adaptor protein (LDLRQP1) mutation is also causal for familial hypercholesterolemia. ${ }^{13}$ The condition is typically characterized by abnormally elevated serum LDL cholesterol levels, a family history of hypercholesterolemia, tendon xanthoma formation, high risk for premature atheroma formation, and a subset may exhibit corneal arcus. ${ }^{5}$ Homozygous or compound heterozygous mutations in $L D L R$ result in the particularly severe form of familial hypercholesterolemia, known as homozygous familial (or type II) hypercholesterolemia, in which hypercholesterolemia is profound, and premature cardiovascular disease can present in childhood. Therapy has included lipid lowering therapy (statins with or without ezetimibe, a cholesterol absorption inhibitor),${ }^{14}$ lipoproteinapheresis, plantsterolsupplementation, ${ }^{15}$ or new classes of agents including lomitapide and mipomersen. ${ }^{13}$

PHT2HC was first described in $1974^{7}$ following unsuccessful identification of other potential causes for hypercholesterolemia in a case of profound hypercholesterolemia not caused by LDLR defect. Cases presenting with this condition, whose etiology remains undefined, also exhibited remarkably elevated cholesterol levels with normal triglyceride levels and presentation of cutaneous and tendon xanthomas during childhood but lacked familial history of hypercholesterolemia in first degree relatives..$^{7-9}$ Whereas these patients were at high risk for early atherogenesis, significant reduction in serum cholesterol was achieved in response to dietary therapy incorporating a low fat, low cholesterol diet in combination with administration of bile acid resin. ${ }^{7-9}$ Further, patients with PHT2HC exhibit normal LDL receptor function. ${ }^{16}$ Based on genetic analysis, Rees et $a{ }^{17}$ found that large platelet size is a characteristic hematological presentation in phytosterolemia, suggesting that the platelet size should be noted in patients with hypercholesterolemia.

Sitosterolemia, a very rare disease, is associated with inability to effectively eliminate plant sterols. This condition also features tendon xanthoma formation as a clinical presentation and is typically associated with normal or only moderately elevated plasma cholesterol concentrations, with cholesterol levels responsive to dietary intervention, consistent with findings of reduced HMG-CoA reductase activity in sitosterolemia, ${ }^{3,18}$ and therefore overlap with some criteria for PHT2HC. However, an additional rare documented presentation of sitosterolemia includes profound hypercholesterolemia and xanthomas in childhood. ${ }^{19-22}$ These patients with sitosterolemia may also exhibit stomatocytosis and macrothrombocytopenia, as described in the present case. Further, these patients do not have family histories of hypercholesterolemia (unless coincidental), and like our index patient, exhibit normal LDL receptor function in in vitro assays. ${ }^{6,16}$

The genetic underpinnings of sitoserolemia were elucidated by Berge et al, ${ }^{23} \mathrm{Lu}$ et $\mathrm{al},{ }^{24}$ and Lee et $\mathrm{al}^{25}$ following mapping of causal genetic mutations in two highly homologous genes in the $S T S L$ locus on chromosome 2p21. Specifically, mutations in $A B C G 5$ or $A B C G 8$ impede dimerization of the gene expression products, sterolin 1 or 2 , respectively, resulting in prevention of expression at the cellular lumen of canalicular hepatocytes and intestinal brush border enterocytes, where they normally function as efflux pumps to extrude phytosterols into bile for eventual incorporation into chylomicrons and subsequent elimination. ${ }^{26,27}$ Diagnosis is validated via plasma sterol profiling by gas chromatography to determine levels of sitosterol, campesterol and stigmasterol. ${ }^{2-4}$

Only few case reports in patients where sitosterolemia was recognized as a cause of PHT2HC have been previously reported including three Japanese reports of two unrelated subjects and one pair of sisters, ${ }^{19-21}$ and one report on two unrelated Chinese patients, ${ }^{22}$ with a history of xanthoma development during childhood. In 2001, Lee et $\mathrm{al}^{28}$ were the first to demonstrate that subjects identified as pseudohomozygous familial hypercholesterolemia had sitosterolemia. Another potential case in an African American child with a profile similar to our case was reported as sitosterolemia. ${ }^{11} \mathrm{~A}$ recent case series reported in Europe by Hansel et al ${ }^{29}$ presented follow up in five adult cases genetically confirmed for a sitosterolemia diagnosis who presented with xanthomas during childhood. These, like our case, presented with what the authors termed as "transient hypercholesterolemia" that was responsive to dietary intervention, although, as in Belamarich's report, ${ }^{11}$ there was no diagnosis of PHT2HC. Two sisters in his report matched criteria for PHT2HC due to lack of family history of hypercholesterolemia, whereas familial hypercholesterolemia could not be ruled out based on data presented for the other cases. No cardiac disease development over time was documented in these confirmed sitosterolemic patients. The authors posited that premature development of cardiovascular disease reported in some patients with sitosterolemia was likely not a function of the elevations in phytosterol levels. Similarly, cardiology findings were normal in our index case.

Diagnosis of sitosterolemia remains most challenging in children. Pediatric patients may present planar, tuberous, or tuberoeruptive xanthomas in various anatomical locations. Buttock xanthomas should prompt consideration for this disorder. Notably, affected children may present with elevated cholesterol responsive to dietary intervention. However, 
differentiation of sitosterolemia from familial hypercholesterolemia is essential, since conventional highvegetable (plant) oil cholesterol-lowering diets are contraindicated in the sitosterolemic patient where dietary therapy aims to delimit phytoserol accumulation in the body. ${ }^{3}$ Moreover, incomplete diagnostic evaluation may lead to iatrogenic deterioration of the patient's condition, as in our patient, where development of thrombocytopenia prompted further testing to arrive at an accurate diagnosis. Lack of family history, presence of xanthoma, and normal LDL receptor function in our subject was consistent with PHT2HC. The sitosterolemia diagnosis, however, was contingent on demonstration of elevated plant sterol concentrations. Notably, caution must be exercised in conducting phytosterol determinations in very young formula-fed infants, since diagnosis of sitosterolemia may be further confounded due to high content of plant sterols in formula.

In the present case, we did not have the opportunity to carry out DNA mutation analysis for $A B C G 5$ or $A B C G 8$ mutations. In addition, ezetimibe was not prescribed in this patient, although that has become a standard therapy since the time this patient was diagnosed, and its use can ameliorate platelet defects. ${ }^{30}$

In summary, it is important to consider a differential diagnosis in children presenting with profound hypercholesterolemia with a probable familial hypercholesterolemia diagnosis. Further, cases in which familial hypercholesterolemia is not confirmed, who may be labelled as PHT2HC, should be screened for sitosterolemia despite its rarity. Accurate diagnosis is critical to appropriate dietary management. Standard dietary therapy for hypercholesterolemia is not therapeutic in patients with undiagnosed sitosterolemia presenting with clinical features consistent with PHT2HC. Whereas plasma cholesterol was reduced in our patient by dietary measures, reduction in plasma plant sterols levels proved resistant to low-fat dietary therapy alone and only improved with cholestyramine administration. Currently, clinical management with inclusion of ezetimibe as a therapeutic adjunct is recommended as a safe, effective cholesterol lowering agent in the context of long-term use. ${ }^{31,32}$ Ezetimibe inhibits NPC1L1 sterol resorption at the level of the intestinal lumen. ${ }^{33}$

Based on our experience and only rare reports in the historical literature, we underline the necessity of recognizing PHT2HC, especially in pediatric patients, and recommend testing patients with PHT2HC for sitosterolemia, which may be one of the more common etiologies. Further, pediatric sitosterolemic cases reported to date have exhibited variablilty in clinical presentation and association with premature atherosclerosis. In fact, based on recent historical review of the literature, premature atherosclerosis has not been suggested as a distinguishing feature of sitosterolemia. ${ }^{31}$ Finally, Silbernagel et $\mathrm{al}^{34}$ recently reported existence of risk alleles in $A B C G 8$ and $A B O$ variants in association with elevated cholesterol and cardiac disease, suggesting that cardiovascular disease risk may be a function of the causal mutation. Improvement of cholesterol levels with dietary intervention, as observed in our case, and adjunctive treatment, would be expected to decrease future cardiovascular risk.

\section{Acknowledgements}

This paper is dedicated in memory of William E. Connor, MD for his invaluable intellectual contributions and expertise in making the diagnosis.

Fibroblast LDL receptor activity was kindly provided by Dr. Joachim Thiery, Institut für Klinische Chemie, Klinikum Großhadern, Ludwig-Maximilians-Universität, München, Germany, before institution of dietary therapy. The "Metab-L" electronic mailing list for inborn errors of metabolism has kindly been hosted on the servers of Kommunikationsnetz Franken e.V. KNF, Erlangen, Germany, at http://www. franken.de/lists/metab-1/index.html since 1995 and is supported by Nutrica GmbH, Allee am Röthelheimpark 11, 91052 Erlangen, Germany.

Preparation of the paper was aided by Dr. med. Stefan Razeghi, then Universitätsklinik für Kinder und Jugendliche, Erlangen, Germany, Metabolic Division, with expert editorial assistance from Ingrid Glurich, $\mathrm{PhD}$ and Marie Fleisner.

\section{References}

1. Bhattacharyya AK, Connor WE. $\beta$-Sitosterolemia and Xanthomatosis. J Clin Invest 1974;53(4):1033-1043.

2. Björkhem I, Boberg KM. Inborn errors in bile acid biosynthesis and storage of sterols other than cholesterol. In: Scriver CR, Beaudet AL Sly WS, Valle D,eds. The Metabolic and Molecular Bases of Inherited Disease. 7th edition. New York: McGraw-Hill Inc; 1995. 2088-2099.

3. Salen G, Shefer S, Nguyen L, Ness GC, Tint GS, Shore V. Sitosterolemia. J Lipid Res 1992;33(7):945-955

4. Bhattacharyya AK, Connor WE, Lin DS, McMurry MM, Shulman RS. Sluggish sitosterol turnover and hepatic failure to excrete sitosterol into bile cause expansion of body pool of sitosterol in patients with sitosterolemia and xanthomatosis. Arterioscler Thromb Vasc Biol 1991;11(5):1287-1294.

5. Sibley C, Stone NJ. Familial hypercholesterolemia: a challenge of diagnosis and therapy. Cleve Clin J Med 2006;73(1):57-64.

6. Teupser D, Thiery J, Walli AK, Seidel D. Determination of LDL- and scavenger-receptor activity in adherent and nonadherent cultured cells with a new single-step fluorometric assay. Biochim Biophys Acta BBALipids Lipid Metab 1996;1303(3):193-198.

7. Morganroth J, Levy RI, McMahon AE, Gotto AM Jr. Pseudohomozygous type II hyperlipoproteinemia. J Pediatr 1974;85(5):639-643.

8. Hamada K, Tanaka T, Yoshii O, et al. Pseudohomozygous type II hyperlipoproteinemia. Jpn J Hum Genet. 1982;27:259-264.

9. Mishkel MA. Pseudohomozygous and pseudoheterozygous type II hyperlipoproteinemia. Am J Dis Child 1976;130(9):991-993 
10. Renner C, Razeghi S, Richter T, Ueberall MA, Schless A. Metab-L: an electronic mailing list on inborn errors of metabolism. Acta Paediatr 1997;86(8):892-894.

11. Belamarich PF, Deckelbaum RJ, Starc TJ, Dobrin BE, Tint GS, Salen G. Response to diet and cholestyramine in a patient with sitosterolemia. Pediatrics 1990;86(6):977-981

12. Goldstein JL, Brown MS. Familial hypercholesterolemia. In: Scriver CR, Beaudet AL Sly WS, Valle D, eds. The Metabolic Basis of Inherited Disease. 6th edition New York: McGrawHill Inc; 1989. 1215-1250.

13. Najam O, Ray KK. Familial hypercholesterolemia: a review of the natural history, diagnosis and management. Cardiol Ther 2015;4:25-38

14. Tsubakio-Yamamoto K, Nishida M, Nakagawa-Toyama Y, Masuda D, Ohama T, Yamashita S. Current therapy for patients with sitosterolemia - effect of ezetimibe on plant sterol metabolism. J Atheroscler Thromb 2010;17(9):891-900.

15. Machado VA, Fonseca FA, Fonseca HA, et al. Plant sterol supplementation on top of lipid-lowering therapies in familial hypercholesterolemia. Int J Cardiol 2015;184:570-572.

16. Masana L, Joven J, Rubiés-Prat J, Lewis B. Low density lipoprotein metabolism and receptor studies in a patient with pseudohomozygous familial hypercholesterolaemia. Acta Paediatr 1990;79(4):475-476

17. Rees DC, Iolascon A, Carella M, O'marcaigh AS. Kendra Jr, Jowitt SN, Wales JK, Vora A, Makris M, Manning N, Nicolaou A, Risher J, Mann A, Machin SJ, Clayton PT, Gasparini P, Stewart GW. Stomatocytic haemolysis and macrothrombocytopenia (Mediteranean stomatocytos/ mnacrothrombocytopenia) is the haematological presentation of phytosterolaemia. Br J Haematol 2005;130:297-309.

18. Nguyen LB, Salen G, Shefer S, et al. Deficient ileal 3-hydroxy3-methylglutaryl coenzyme A reductase activity in sitosterolemia: Sitosterol is not a feedback inhibitor of intestinal cholesterol biosynthesis. Metabolism 1994;43(7):855-859.

19. Fujita M, Okamoto S, Shirai K, Saito Y, Yoshida S. Pseudohomozygous type II hyperlipoproteinemia. Dermatology 1991;182(2):94-97.

20. Matsuo I, Yoshino K, Ozawa A, Ohkido M. Phytosterolemia and type IIa hyperlipoproteinemia with tuberous xanthomas. J Am Acad Dermatol 1981;4(1):47-49.

21. Yoshida A, Naito M, Miyazaki K. Japanese sisters associated with pseudohomozygous familial hypercholesterolemia and sitosterolemia. J Atheroscler Thromb 2000;7(1):33-38.

22. Low LCK, Lin HJ, Lau KS, Kung AWC, Yeung CY. Phytosterolemia and pseudohomozygous type II hypercholesterolemia in two Chinese patients. J Pediatr 1991;118(5):746-749.

23. Berge KE, Tian H, Graf GA, et al. Accumulation of dietary cholesterol in sitosterolemia caused by mutations in adjacent ABC transporters. Science 2000;290(5497):1771-1775.

24. Lu K, Lee MH, Hazard S, et al. Two genes that map to the STSL locus cause sitosterolemia: genomic structure and spectrum of mutations involving sterolin-1 and sterolin-2, encoded by ABCG5 and ABCG8, respectively. Am J Hum Genet 2001;69(2):278-290.

25. Patel SB, Lee M-H, Lu K, et al. Identification of a gene, ABCG5, important in the regulation of dietary cholesterol absorption. Nat Genet 2001;27(1):79-83.

26. Yu XH, Qian K, Jiang N, Zheng XL, Cayabyab FS, Tang CK. ABCG5/ABCG8 in cholesterol excretion and atherosclerosis. Clin Chim Acta 2014;428:82-88.

27. Patel SB. Recent advances in understanding the STSL locus and ABCG5/ABCG8 biology. Curr Opin Lipidol 2014;25(3):169-175
28. Lee MH, Lu K, Patel SB. Genetic basis of sitosterolemia. Curr Opin Lipidol 2001;12(2):141-149.

29. Hansel B, Carrié A, Brun-Druc N, et al. Premature atherosclerosis is not systematic in phytosterolemic patients: Severe hypercholesterolemia as a confounding factor in five subjects. Atherosclerosis 2014;234(1):162-168.

30. Othman RA, Myrie SB, Mymin D, et al. Ezetimibe reduces plant sterol accumulation and favorably increases platelet count in sitosterolemia. J Pediatr 2015;166(1):125-131.

31. Salen G, von Bergmann K, Lütjohann D, et al; Multicenter Sitosterolemia Study Group. Ezetimibe effectively reduces plasma plant sterols in patients with sitosterolemia. Circulation 2004;109(8):966-971.

32. Lütjohann D, Von Bergmann K, Sirah W, et al. Long-term efficacy and safety of ezetimibe $10 \mathrm{mg}$ in patients with homozygous sitosterolemia: a 2-year, open-label extension study. Int J Clin Pract 2008;62(10):1499-1510.

33. Othman RA, Myrie SB, Jones PJH. Non-cholesterol sterols and cholesterol metabolism in sitosterolemia. Atherosclerosis 2013;231(2):291-299.

34. Silbernagel G, Chapman MJ, Genser B, et al. High intestinal cholesterol absorption is associated with cardiovascular disease and risk alleles in ABCG8 and ABO: evidence from the LURIC and YFS cohorts and from a meta-analysis. J Am Coll Cardiol 2013;62(4):291-299.

\section{Author Affiliations}

Christian Renner, MD*; William E. Connor, $M D^{*}$; and Robert D. Steiner, $M D^{t s}$

*Kinder und Jugendart Praxis, Pfleggasse 31, D-94469

Deggendorf, Germany

tDepartment of Medicine, Oregon Health \& Science

University, Portland, Oregon, USA

${ }^{*}$ Department of Pediatrics and Molecular and Medical Genetics, Oregon Health \& Science University, Portland, Oregon, USA

${ }^{\S}$ Marshfield Clinic Research Foundation, Marshfield, USA 